NOTAS DE LEITURA 


\section{CHOMSKY NO BRASIL: UMA BREVE NOTA DE LEITURA}

Carlos Alberto Faraco*

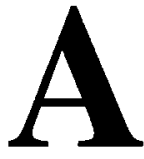

visita de Chomsky ao Brasil em 1996 foi, certamente, um acontecimento memorável. Para os adeptos, a tão sonhada possibilidade de ouvir lições diretamente da boca do mestre (para alguns, inclusive, a oportunidade de um paradoxal - à medida que estamos no espaço da ciência - êxtase quase religioso).

Para os críticos, a ocasião de revisita aos velhos pressupostos do sistema chomskyano de pensamento e, é claro, às velhas manhas de sua retórica.

A publicação das conferências e da entrevista com Mike Dillinger e Adair Palácio, em português e inglês, pela revista $D E L T A$ (v. 13, número especial, 1997) deu, de imediato, circulação internacional a essa documentação e permitiu já as primeiras reações, como, por exemplo, a resenha crítica de Joseph (1999) a que nos reportaremos adiante.

A primeira conferência, "Novos horizontes no estudo da língua", na medida em que não vai além de uma espécie de visita técnica (feita, diga-se de passagem, com admirável clareza didática) às coordenadas analíticas da gramática gerativa, interessa fundamentalmente ao público interno, isto é, aos que praticam a análise gerativa e aos que se iniciam nela.

Dizemos isso, porque modelos enquanto tais parecem ser, na prática, não criticáveis do exterior. Para submeter um modelo à crítica é preciso aceitar seu

* Cefe/PR. 
objeto, seus objetivos, sua lógica argumentativa e, principalmente, a cosmovisão que o sustenta. Sem esse quadro mais amplo, o modelo não passa de um aparato organizador de dados desprovido de efetiva significação heurística, o que, aliás, o próprio Chomsky destaca às páginas 58-59.

Um público menos restrito (em que nos incluímos) encontrará mais o que ler na segunda conferência ("Conhecimento da história e construção teórica na linguística moderna"), que se apresenta como um exercício de história da linguística (e, por isso, interessa, certamente, a todos quantos se consideram lingüistas ou se dedicam à história das ciências); e na entrevista, em que, além de questões mais técnicas, há também as de temas mais gerais.

Num primeiro balanço de leitura, é impossível não registrar o fato de que Chomsky disse pouco (ou quase nada) além do que podemos ler em seus outros textos, o que não deixa de ser um tanto quanto frustrante.

Nesse sentido, as "Conferências do Brasil" não terão a repercussão que a seu tempo tiveram as "Conferências de Pisa" e as "Conferências de Manágua". Não queremos crer que Chomsky tenha subestimado sua platéia. Parece-nos mais plausível pensar que a mera reiteração do já-dito seja apenas um interessante sinal dos tempos. O futuro dirá.

Por outro lado, é impossivel não reagir a certas manhas do dizer chomskyano. Mesmo um leitor acostumado com os tradicionais gestos retóricos - invariavelmente presentes nos textos do autor - de incontida louvação de si e de seus seguidores (tudo que se faz do lado do "bem" é interessante, relevante, pertinente) e de seca destratação dos outros (tudo que se faz do lado do "mal" é desinteressante, irrelevante, desnecessário, não pertinente) não deixará de se surpreender com algumas asserções do visitante no correr de suas falas em terras brasileiras.

Particularmente notável, nesse sentido, é a forma rápida de descartar leitores críticos. No fundo, não são necessários argumentos e contra-argumentos: tudo se resolve por meio do velho e simples gesto de degradar os adversários: ou eles não ultrapassaram a página 2 de seu livro Lingüística cartesiana (p.130); ou eles sempre interpretam erroneamente as suas palavras (p. 215).

Quanto ao primeiro lance de degradação do adversário, vale a pena citar Joseph que diz (p. 425):

Now, anyone who has actually read reviews of the book such as those by Salmon (1969) and Aarsleff (1970) will know at once that Chomsky's objection is a complete red herring, having nothing whatever to do with the contents of these serious and 
careful discussions of his work. It seems that he has never allowed himself to take in the full force of the criticism, but instead shunted the negative reviewers into the "bad guys" cupboard and abandoned any serious interest in the history of linguistics, rather than reformulate his ideas on solider ground.

E, quanto ao mal interpretar, é interessante lembrar que isso acontece, segundo Chomsky, porque não vivemos num mundo sensato (p. 215).

Neste nosso insensato mundo, dizemos uma palavra como "conhecimento" e somos "soterrados por idéias dúbias provenientes da epistemologia, da psicologia e da filosofia da mente que tentam explicar o que é conhecimento" (p. 215).

Se tentarmos entender que características teria esse tal mundo sensato de Chomsky, concluiremos, lendo o texto que segue imediatamente ao citado acima, que seria um mundo em que as palavras seriam unívocas e significariam apenas e exatamente o que nosso autor gostaria que elas significassem.

Parece difícil não ver aí um indisfarçável gesto de autoritarismo intelectual, para dizer o menos: é sensato o mundo que jogue de acordo com as minhas regras.

Essa nossa leitura (certamente mais uma daquelas que sempre interpretam mal as palavras...) se reforça quando encontramos Chomsky à p. 220 ocupado em asseverar o "verdadeiro significado" de idealização, justamente porque "é um termo que pode provocar alguns mal-entendidos".

Em outros termos, como as pessoas, neste nosso insensato mundo, vivem interpretando mal as palavras, é preciso alguém para dizer qual o seu "verdadeiro significado"!

Mas nosso mundo não é apenas insensato, elc também não é suficientemente "racional" e "lógico", em especial quando as pessoas contam a história da linguística (p. 129).

O que fazemos, segundo Chomsky, neste mundo algo irracional e ilógico? Bem, ficamos ocupados, ao tratar da história da lingüística, em "descrever os fatos reais, o que realmente aconteceu", o que não é lá muito interessante, porque "é uma história que nunca foi contada corretamente" (o grifo, obviamente, é nosso).

Essa mesma idéia volta na página seguinte quando se lê: "Na história da lingüística como um todo, existem bons trabalhos acadêmicos sobre aspectos particulares, mas, na minha visão, eles frequientemente interpretam erroneamente o que aconteceu" (de novo, o grifo é nosso). 
Se a história nunca foi contada corretamente; se freqüentemente os bons trabalhos interpretam erroneamente o que aconteceu (questão que retorna em outros momentos da segunda conferência), a conclusão óbvia parece ser que precisamos de alguém que nos conte "a verdadeira história"!

Não será, portanto, surpresa para o leitor encontrar, na página 200, o seguinte enunciado sobre o início da gramática gerativa: "Esta é a verdadeira história, embora não seja contada dessa maneira" (o grifo é nosso).

Mas Chomsky não se apresenta apenas como quem conta a "verdadeira" história. Ele nos diz mais: "Acho que uma perspectiva histórica é importante, mas quase ninguém mais faz isso, além de nós" (p. 195). Portanto, além de nos contar a "verdadeira" história, ficamos também sabendo que quase só ele (ou eles, os gerativos - há uma ambigüidade de difícil solução neste nós) tem (têm) uma perspectiva histórica: "Não é o tipo de tema que interessa às pessoas na Lingüística ou na Filosofia, nem mesmo àqueles [surpresa das surpresas!] que estudam História da Lingüística ou História da Filosofia"!

Como proceder, então, para fazer história da lingüística? A resposta nos é dada no início da segunda conferência. A maneira "mais interessante para abordar a questão seria indagar como as coisas deveriam ter ocorrido num mundo mais racional (...), num mundo mais lógico" (p. 129).

Estamos convencidos hoje de que não há um único modo de abordar questões de história (de uma ciência, por exemplo). Em qualquer processo histórico, reconhece-se a existência de múltiplos estratos passíveis de serem explorados e não redutíveis a um só esquema linear. Aprendemos a desconfiar de todas as tentativas de reduzir a complexidade dos processos históricos a um sistema de relações homogêneas. Aprendemos também a operar com a descontinuidade e a entender os processos históricos como espaços de dispersão.

Abordar, contudo, as questões históricas indagando "como as coisas deveriam ter ocorrido num mundo mais racional, mais lógico" parece estar fora de qualquer metodologia histórica aceitável, constituindo antes um trabalho de ficção.

É claro que ninguém está proibido de fazer ficção, especialmente quando se trata de situar o trabalho pessoal no contexto mais amplo de uma certa ciência. No entanto, cabe sempre perguntar se é apropriado classificar o modo ficcional como "verdadeira história do tema" (p. 148), como insiste nosso conferencista. Talvez Joseph tenha razão: "No intelligent person could take what Chomsky says here seriously" (p. 423).

O mesmo comentário serve, certamente, a propósito das bombásticas (para não dizer megalômanas) afirmações do ilustre visitante de que a teoria dos princípios e parâmetros "foi a primeira teoria de linguagem genuína a ser 
produzida nesses 2.500 anos" (p. 206) e de que "provavelmente se aprendeu mais sobre a linguagem nos anos 80 do que nos 2.500 anos anteriores"(p. 207)! Muito embora, ressalta-se logo à frente, tudo que se produziu tivesse de ser abandonado, porque não passava de "uma tecnologia descritiva que funciona, mas que está errada porque não é motivada" (p. 208).

A propósito das duas afirmações sobre os anos 80 , diz Joseph, com humor e propriedade (p. 424):

This sort of boast is liable to lower the circulation base of HL [Historiographia Linguistica] by making some readers' blood pressure explode and others die laughing. It may help the former, though not the latter, to know that this unprecedented accumulation of linguistic knowledge has already been flushed down the toilet of history.

Talvez devêssemos explorar um pouco a forma estereotipada com que Chomsky trata (ver p. 81-82 e 205) dos professores universitários europeus (e, por tabela, dos professores universitários latino-americanos), pelo muito que isso tem a nos dizer sobre sua visão de mundo. Além de outras afirmações do autor sobre a história da linguística. Contudo, os pontos acima apresentados parecem o bastante para os propósitos desta breve nota de leitura, isto é, tornar um pouco mais visíveis certas velhas práticas cabotinas do incansável mestre do MIT e, com isso, poder observar com um olhar mais crítico seus dizeres num contexto que tende, algumas vezes, a ser excessivamente laudatório.

Se aqueles pontos não são, evidentemente, suficientes para diminuir sua importância teórica na linguística do século XX e sua exuberância intelectual, podem, pelo menos, ser úteis para percebermos a relevância da observação do próprio Chomsky (p. 209) - talvez a mais pertinente de todo o conjunto publicado pela DELTA - sobre a primeira qualidade dos estudantes de linguística: "Acima de tudo, você não deve levar muito a sério qualquer coisa que ouvir de qualquer pessoa que seja uma autoridade."

\section{REFERÊNCIAS}

AARSLEFF, Hans. The History of Linguistics and Professor Chomsky. Language, 46, p. 570-585, 1970. 
FARACO, C. A. Chomsky no Brasil: uma breve nota de leitura

Chomsky no Brasil/Chomsky in Brazil (edição bilíngüe). DELTA - Revista de Documentação de Estudos em Lingüística Teórica e Aplicada, 13, 1997.

JOSEPH, John. E. Review of Chomsky no Brasil/Chomsky in Brazil. Historiographia Linguistica, XXVI:3, p. 421-428, 1999.

SALMON, Vivian. Review of Chomsky (1966). Joumal of Linguistics, 12, p. 165-187, 1969. 